\title{
La posguerra en Guatemala Justicia, perdón y reconciliación
}

\author{
Michael K. Duffey, \\ Universidad Marquette, \\ Wisconsin
}

\section{Introducción}

El arzobispo Desmond Tutu, presidente de la Comisión de la Verdad y la Reconciliación de Sudáfrica (CVR), insistió en que tras el conflicto en África del Sur, el proceso de sanación no podía comenzar con la justicia penal, sino únicamente con el perdón. "Sin perdón, no hay futuro", dijo'. Algunas de las víctimas perdonaron a los agentes del apartheid por los crímenes que estos habían cometido. Pero la pregunta es cómo y cuándo ocurre el perdón. A raíz del 11 de septiembre de 2001, el papa Juan Pablo II reconoció que hay que poner en práctica la justicia penal, pero advirtió del peligro de grandes represalias ${ }^{2}$. El fracaso en perdonar y trabajar por la justicia solo perpetúa los ciclos mortales de la violencia. El papa declaró que "no hay paz sin justicia, ni justicia sin perdón". Pero ¿por qué ha de haber perdón si hay que practicar la justicia?

La finalidad de este ensayo es explorar la relación entre justicia, perdón y reconciliación en la posguerra de Guatemala. Compararé las experiencias guatemaltecas con las sudafricanas, especialmente las que ha recogido la CVR. Añadiré una perspectiva teológica, y mi referencia última serán los esfuerzos de la Iglesia católica guatemalteca por conseguir sanación en este país de grandes sufrimientos ${ }^{3}$.

1. D. Tutu, No future without forgiveness, Nueva York, Doubleday, 1999, p. 54.

2. Juan Pablo II, "No Peace without Justice. No justice without Forgiveness", Ciudad del Vaticano, 2002.

3. Agradezco las sugerencias de varias personas que trabajan por la sanación y la paz. Entre ellas, el padre Dean Brackley, S.J. [fallecido el 16 de octubre de 2011], exprofesor de teología en la Universidad Centroamericana en San Salvador. 
Analizar la justicia, el perdón y la reconciliación exige proceder con cautela. Quien quiere adentrarse en el mal debe guardar silencio, escuchar a las víctimas y dejarlas hablar. Estas experiencias son las más importantes. Sin embargo, al usar la palabra "víctima", hay que tener en cuenta que estas no son pasivas. Han reconstruido sus vidas desde las cenizas con gran valor. Debemos vivir en solidaridad con su dolor, pero sin sentir lástima por ellas ${ }^{4}$. Me ayudó a no caer en esta tentación la observación de Antjie Krog en su estupendo libro sobre la CVR, País de mi calavera. La autora hace notar cómo los extranjeros llegaron a Sudáfrica, estuvieron presentes durante algunos días en las audiencias de la CVR, y después regresaron a sus casas para analizar críticamente todo el proceso. Su conclusión es que, ciertamente, hay que evaluar las estructuras y los métodos de las comisiones de la verdad, pero la sabiduría más profunda proviene de la experiencia de una sociedad, tanto las del pasado como las del presente. El trabajo de reconciliación llevará muchos años y, por ello, toda evaluación puede ser prematura. Sin embargo, lo que ya se puede aprender de esas comisiones puede ser útil para el proceder de otras sociedades que están en la misma búsqueda de verdad, justicia, perdón y reconciliación.

Desde 1954, cuando Estados Unidos saboteó al Gobierno de Jacobo Arbenz, que estaba comenzando la primera "primavera democrática" del país, gobernaron juntas militares que pusieron al Ejército contra insurgentes y civiles por igual. Finalmente, en 1960, la resistencia hizo que estallase una guerra civil que duró 36 años. Cuando en 1996 se firmó el Acuerdo de Paz entre un Ejército respaldado por el Gobierno y las fuerzas rebeldes, más de 200,000 personas, en su mayoría mayas, habían sido atrapadas en el cruce de fuego y murieron asesinadas. La Iglesia católica guatemalteca ha dado pasos para sanar a las víctimas que quedaron traumatizadas por esa época de genocidio - gente que ha continuado viviendo en pobreza e impotencia, con sus culturas indígenas casi destruidas-.

He podido conocer a varias personas del departamento de Quiché, ubicado en el altiplano central. Comienzo con la narración de la historia de uno de los sobrevivientes, al que llamaré Manuel. Sufrimientos como el suyo han sido compartidos por miles.

Nomfundo Walaza es director ejecutivo del Desmond Tute Peace Centre en Ciudad del Cabo, Sudáfrica. Deseo expresar un agradecimiento especial a un agente de pastoral en Guatemala que desea permanecer anónimo.

4. Los supervivientes que, valientemente, buscan información sobre sus seres queridos desaparecidos en el derecho internacional son tenidos por "víctimas de la tortura". También ellos buscan reconstruir sus vidas con gran valor. 


\section{La historia de Manuel}

A los 13 años, Manuel empezó a trabajar en una parroquia católica en Quiché, llevada por los padres del Sagrado Corazón que habían venido de España. Recuerda los proyectos que tenía la parroquia para mejorar la situación de vida de la gente: ganadería, crianza de abejas y plantación de árboles de manzana. Sin embargo, todo cambió en 1980. Forzada por el Ejército, la guerrilla tuvo que salir de Ciudad de Guatemala y huyó hacia las montañas del altiplano. La región maya conocida como el Triángulo Ixil, rodeada por los pueblos de Nebaj, Cotzal y Chajul en el altiplano, pasó a ser el epicentro de la estrategia del Ejército para acabar con la guerrilla y con quien fuera acusado de apoyarla, en su mayoría catequistas de la Iglesia, promotores de salud y líderes de la comunidad. Eventualmente, toda la población maya fue perseguida.

Manuel nunca podrá olvidar el 12 de abril de 1980. Ese día, los soldados llegaron a su aldea y comenzó la matanza. Él no estaba en su casa, pero allí mataron a su esposa, a su hijo mayor de dos años, a los abuelos y a sus tíos. Manuel enterró rápidamente a su familia y huyó a las montañas. Esa primavera, el Ejército asesinó a miles de mayas del Triángulo Ixil y quemó la mayoría de aldeas de la parroquia. Los soldados ocuparon el pueblo, convirtieron la iglesia en un cuartel y el convento en un centro de comandos y de tortura. En frente de la iglesia pusieron un centro de detención para mujeres y niños. Fuera del pueblo se establecieron las denominadas "aldeas modelos", para reorganizar a los sobrevivientes mayas.

Durante 14 años, Manuel vivió escondido en las montañas más altas, con mucho bosque, cerca de la frontera mexicana. La red de esas comunidades pasó a ser conocida como Comunidades de Población en Resistencia (CPR). Estando en las montañas, Manuel se casó y comenzó una segunda familia.

Cuando la primera familia de Manuel fue asesinada, el obispo de Quiché, Juan José Gerardi, fue objeto de dos intentos de asesinato. En 1980, suspendió las actividades de la diócesis (que se reanudaron en 1983) e instó a que salieran todos los sacerdotes y religiosas con la esperanza de que disminuyeran los atroces ataques a los trabajadores de la Iglesia. El sacerdote y pastor de Manuel se quedó, y en diciembre de 1980 fue testigo de la masacre de una docena de mujeres mayas desarmadas frente a la iglesia. Seis meses después, él mismo fue asesinado, como lo fueron otros dos sacerdotes españoles de parroquias cercanas. Aunque no sea sorprendente, en una foto especialmente preocupante, aparece un soldado estadounidense de pie a la entrada de la iglesia, la que después quedó convertida en cuartel militar.

Cuando disminuyó la violencia, la primera iniciativa de la Iglesia católica fue acompañar a sobrevivientes que, como Manuel, vivían en las montañas del altiplano del centro de Guatemala y en los campamentos mexicanos para que 
pudieran regresar a sus lugares ancestrales ${ }^{5}$. En las aldeas que habían abandonado, la mayoría de los refugiados no encontraron nada, y los nuevos ocupantes reclamaban la propiedad de sus tierras de maíz. Unas pocas comunidades se unieron para recuperar sus tierras. Fue un proceso largo con éxito limitado.

La segunda iniciativa fue la creación en 1995 de la Comisión de la Verdad. Durante tres años, cientos de trabajadores de pastoral recogieron testimonios de los supervivientes. En 1998, la Iglesia publicó un informe de cuatro volúmenes, Recuperación de la Memoria Histórica (Remhi) ${ }^{6}$. La Remhi contenía miles de nombres de víctimas, pero no identificaba a ninguno de los victimarios. Quedaron registradas más de 52,000 violaciones de los derechos humanos y de la ley humanitaria. El Informe atribuyó el 89.65\% de las violaciones al Ejército, a la Policía y a las unidades paramilitares. Cuatro por ciento de las violaciones fueron atribuidas a las fuerzas guerrilleras ${ }^{7}$. Monseñor Juan Gerardi publicó el Informe en 1998. Dijo que su propósito era "ver las raíces de la injusticia y la ausencia de valores". Dos días después, monseñor fue asesinado. Al año siguiente, Naciones Unidas dio a conocer el informe de su comisión de la verdad Memorias del silencio, de la Comisión para el Esclarecimiento Histórico (CEH), que coincidía con las conclusiones de la Remhi ${ }^{8}$. En conjunto, ambos informes ofrecieron una larga letanía de formas sádicas de tortura, asesinatos de hombres, mujeres y niños, y del terror de los supervivientes, que han producido años de un temor paralizante. Ambos documentos detallan la peor era de genocidio en la historia moderna guatemalteca y de toda Centroamérica.

En su introducción, monseñor Gerardi mostró su esperanza sobre el resultado de un monumental proyecto, pues se habían recogido testimonios de las víctimas y supervivientes de los 36 años de guerra civil en su país:

Nosotros estamos llamados a la reconciliación (...) La misión de [Cristo] es de reconciliación (...) Su presencia nos llama a ser agentes de reconciliación en esta sociedad quebrantada y tratar de poner a las víctimas y a los causantes

5. También otros grupos practicaron el acompañamiento, incluyendo la Internacional de Brigadas de Paz, voluntarios que se prepararon en la resolución del conflicto de diversos países europeos, Estados Unidos y Canadá.

6. En forma abreviada, Orbis Press publicó en 1999 una versión inglesa como Guatemala: never again.

7. Informe de Recuperación de la Memoria Histórica (Remhi), pp. 289 y ss.

8. Más adelante, haré una comparación entre el CEH y la Comisión de Verdad y Reconciliación en Sudáfrica para dar un juicio de lo que fue posible en Guatemala. Sobre las serias limitaciones con las que tuvo que trabajar la CEH, ver R. Wilson, "Violent Truths: the politics of Memory in Guatemala", Conciliation Resources, 1997. Disponible en http://www.c-r.org/our-work/accord/guatemala/vilent-truths.php. 
dentro del mismo marco de la justicia (...) La conversión es necesaria y depende de nosotros abrir espacios y dar lugar a esa conversión. ${ }^{9}$

Monseñor Gerardi concluyó con la pregunta que Yahvé hace a Caín: ¿Qué has hecho? Desde la tierra, la sangre de tu hermano clama hacia mí” $(\mathrm{Gn} \mathrm{4,10).} \mathrm{Pero}$ ¿quiénes fueron los "Caínes"? En la sección tres, la discusión sobre la reconciliación, analizaré la necesidad de centrarse tanto en los victimarios como en las víctimas, como elemento vital del proceso de reconciliación. Explicaré que es parte esencial del ministerio de las iglesias acoger a quienes han sido excluidos de la comunidad cristiana (o a los que permanecen alejados de ella porque tienen sentido de culpabilidad y miedo). Para sanar a la sociedad guatemalteca, es esencial trabajar para incluir a los victimarios. Las iglesias no pueden ignorar la sanación de los victimarios, así como de las víctimas.

La tercera iniciativa fue empezar el proceso de exhumación de los restos de las víctimas en alrededor de cuatrocientos cementerios clandestinos a lo largo y ancho del altiplano. Los esfuerzos iniciales fueron de la Fundación de Antropología Forense de Guatemala. Las exhumaciones han servido varios propósitos que enumeramos a continuación:

1. Reunir a las víctimas con sus familias y darles digna sepultura. De acuerdo a la cultura maya, sin un entierro digno, los espíritus de los muertos están intranquilos y perturban las vidas de sus familiares. En realidad, las víctimas lloran. Manuel recuerda que a menudo sueña con su esposa, a quien no podía oír cuando ella trataba de hablarle. Manuel cuenta: "Yo me sentía culpable, y volvía a sentir odio por lo que le pasó a mi familia (...) Entonces empecé a ver las exhumaciones como una reunión con la familia. Ya no voy a pasar más tiempo pensando en lo que pasó. Puedo exhumarlos, llevarlos a mi casa y tener un velorio para ellos, llevarlos al cementerio y enterrarlos yo mismo".

2. Decir la verdad sobre lo que ocurrió. Clyde Snow, antropólogo forense que ha trabajado en varios lugares de exhumación en Guatemala, dijo: "Los huesos no mienten"10. Los huesos quebrados, atados, acribillados con agujeros de balas, dicen la verdad de lo que ocurrió. Estas historias mudas no permiten olvidar, e impiden que ocurra el olvido que desean los autores y perpetradores de la violencia. Katarina, que trabajó con el equipo, insistió en que la exhumación de los huesos de mujeres, niños y ancianos contradice la afirmación del Ejército de que habían matado únicamente a guerrilleros ${ }^{11}$.

9. Informe Remhi, op. cit., p. xxiii.

10. Citado por V. Sanford, Secretos enterrados: La verdad y los derechos humanos en Guatemala, Nueva York, Palgrave Press, 2003, p. 47.

11. Entrevista del autor, 29 de febrero de 2008. Traducción del autor. Uno de ocho restos exhumados eran de niños, según Secretos enterrados: Fosas nasivas en Guatemala, de Silvia Gambardella, Suffolk, New Dominion Pictures, 2008. 
Jonathan Moëller, fotógrafo forense y periodista, que estuvo presente en varias exhumaciones, describió el proceso como "un escuchar las voces de aquellos a quienes hemos llamado a luchar contra el olvido"12. Las víctimas son recordadas y honradas. El Informe Remhi pidió al Gobierno que honrara a las víctimas con monumentos locales. Sin embargo, el número y calidad de los monumentos son decepcionantes. Por ejemplo, el monumento en la Plaza de Nebaj, una de las regiones con más alto nivel de masacres en el país, es mínimo y está en mal estado. Se puede dudar de que sea en absoluto un monumento.

3. Identificar positivamente los restos como evidencia potencial en posibles juicios criminales.

Una cuarta iniciativa fue proveer programas de salud mental para tratar la depresión de los sobrevivientes, enfermedades somáticas, sentido de pérdida de sí mismo y de culpa por no haber podido salvar las vidas de sus seres queridos. La profundidad del sufrimiento la expresó así una mujer: "Yo ya no soy una persona"13. Los sobrevivientes hablan de sentir "susto" (pérdida del alma), agotamiento y entumecimiento. Un sobreviviente dijo que "cuando ocurrió la violencia, se fueron las costumbres [se refería especialmente al traje tradicional del hombre, como signo de identidad comunitaria] (...) se fue todo. Ha habido ceremonias mayas y también costumbres católicas aquí, pero cuando ocurrió la violencia, todo cambió (...) Con la violencia, cambió el destino de la población"14. Pastores y catequistas fueron un blanco de la persecución, así como los ancianos y adivinos, y los organizadores comunitarios. Después de la guerra, las comunidades han tenido que lidiar con altos niveles de alcoholismo y violencia, tanto a nivel doméstico como comunal. También desapareció el servicio de los curanderos tradicionales. Manuel observa que hay una gran incidencia de suicidios entre los hijos adolescentes de las víctimas. A diferencia de sus padres, que conocen la fuente de sus sufrimientos, la siguiente generación no sabe cuál es la fuente de su depresión, ansiedad y desesperación.

Aunque con alcance limitado, ya se han iniciado algunos programas de salud mental. Uno de ellos ha sido patrocinado por el Instituto de Psicología de la Universidad Rafael Landívar en Ciudad de Guatemala. En 2007, el "Proyecto de Intervención Psicosocial" envió psicólogos a un buen número de comunidades. $\mathrm{Su}$ enfoque de psicología comunitaria busca hacerse presente en el contexto social y comunal para tratar los efectos debilitantes de la guerra y de la continua

12. J. Moëller, p. 128.

13. J. N. Zur, Memorias violentas: La guerra maya. Viudas en Guatemala, Boulder, Westview Press, 1998, p. 177.

14. Antonio Caba, en entrevista con Elias Lawless, "Los sobrevivientes mayas vs. los genocidios", Parte 1, Guerrilla News Network, 2007, pp. 3-4. 
marginación de los mayas ${ }^{15}$. Un segundo programa ha sido patrocinado por la Universidad del Valle de Guatemala. Ha estudiado los síntomas, ampliamente extendidos, de estrés postraumático, y prepara a promotores locales de salud mental para tratar los traumas creados por la guerra, especialmente síntomas como la falta de capacidad social, desintegración de la comunidad, miedo y desconfianza, desesperación política e impotencia, inhibición social, violencia familiar y social, y el movimiento hacia formas fundamentalistas del cristianismo "que facilita la falsa percepción de seguridad"16.

\section{Justicia}

Voy a tratar los problemas de la justicia penal y de la justicia restaurativa en Guatemala. Dadas las grandes desigualdades de riqueza y poder, es necesario apuntar también a la justicia social. La exclusión de los pobres y de las minorías en la participación política, la lamentable falta de oportunidades de educación y cuidado de la salud, los mecanismos del mercado, que contribuyen al empeoramiento de la pobreza, son en Guatemala, como en toda Centroamérica, la raíz de los grandes conflictos. El problema de la justicia social es un aspecto de la justicia restaurativa sobre el que trataremos más adelante. También es un elemento de la transformación de la organización social necesaria para la reconciliación (ver la sección tres).

\subsection{Justicia penal}

Muchos guatemaltecos quieren que haya un juicio a los autores del genocidio, especialmente al general Efraín Ríos Montt, quien dirigió las masacres durante sus dieciocho meses en la presidencia (1982-1983) ${ }^{17}$. Ríos Montt encabeza ahora el ala derechista del Frente Republicano Guatemalteco. Fue presidente del Congreso de 1999 a 2004, y en 2003 corrió, sin éxito, para presidente. Por su parte, los activistas de derechos humanos trabajan para que haya justicia. Entre otros, la Asociación para la Justicia y Reconciliación, el Centro para la Acción Legal, Conavigua (grupo de apoyo a las viudas) y GAM (grupo de apoyo a los sobrevivientes) han buscado, sin ningún éxito, una acción legal contra Ríos Montt, contra otros generales y contra los perpetradores de otros asesinatos a alto nivel (por ejemplo, el de la antropóloga Myrna Mack en 1990 y el de monseñor Gerardi en 1998). Estos esfuerzos solo han tenido éxito en la acción legal contra unos pocos

15. No conseguí copia de la propuesta de 2008. El reporte puede ser obtenido a través del Instituto de Psicología de la Universidad Rafael Landívar.

16. L. Cazali Leal, "Adaptación de un diagnóstico a la realidad de Guatemala: Trastorno por estrés postraumático" (Guatemala: Universidad del Valle de Guatemala, n. d.), pp. 4-5. Se puede tener acceso al reporte en www.coedu.usf.edu/zalaquett/cic/ad.htm.

17. Ríos Montt fue entrenado en la Escuela de las Américas de Estados Unidos contra la insurgencia. 
perpetradores, de bajo nivel, de crímenes de guerra, pero no contra expresidentes militares. Activistas de derechos humanos, investigadores, procuradores y jueces han sido asesinados o han ido al exilio. Manuel duda de que pueda haber justicia después de 30 años de casi ninguna acción penal. Él deja la justicia a Dios.

El arzobispo Tutu escribió que el desafío del posapartheid en Sudáfrica era "equilibrar las exigencias de la justicia, la responsabilidad, la estabilidad, la paz y la reconciliación"18. La oferta de amnistía de la TRC (Comisión para la Verdad y la Reconciliación) en definitiva solo atrajo a miembros del Ejército de bajo nivel, servicios de inteligencia, escuadrones de la muerte y guerrilleros oponentes al apartheid. No fue aceptada por ningún miembro del Gobierno ni por oficiales militares de alto nivel. Y la mayoría de los que la aceptaron no mostraron remordimiento ni pidieron perdón. Sin embargo, la Comisión para la Verdad y la Reconciliación sí ayudó a las víctimas a seguir adelante y a renunciar a la venganza. Tutu también ha insistido en que la justicia restaurativa por medio de demandas civiles contra los perpetradores, descartada por la forma en que se estipuló la amnistía, no podía conseguir recursos para compensar lo que se debía a las víctimas. De ahí que Tutu imaginó otro tipo de justicia restaurativa: "La gran justicia moral de lograr una sociedad en armonía", lo que es, además, "una característica tradicional de la jurisprudencia africana" expresa el concepto tradicional de ubuntu: "Las personas son personas a través de otras personas; yo soy porque nosotros somos".

Tutu explicó las razones para ofrecer una amnistía en bien de la armonía social a quienes argumentaban que, de esa forma, se pasaba por alto la justicia penal. Varias fueron sus razones a favor de la amnistía.

En primer lugar, sin una garantía constitucional, las fuerzas de la defensa de Sudáfrica no hubieran negociado un convenio, el país hubiera permanecido muy dividido y sujeto a continuas represalias y venganzas. En segundo lugar, hubiera sido muy difícil reunir evidencias para decidir si había habido culpa "más allá de toda duda razonable", lo que además hubiera significado una gran carga y un enorme gasto que habría recaído sobre el sistema judicial. En tercer lugar, en el proceso penal, "la parte perjudicada es realmente el Estado" más que la víctima ${ }^{20}$. En cambio, la provisión de amnistía ofrecía a los supervivientes respuestas a las preguntas de qué ocurrió a sus seres queridos y ofreció cierto sentido de cercanía a los familiares de las víctimas. Con todo, muchos en Sudáfrica no creen que haya habido reconciliación.

18. D. Tutu, No future without forgiveness, op. cit., p. 23.

19. R. I. Rothberg y D. Thompson (eds.), Verdad vs. justicia: La moralidad de la comisiones de la verdad, Princeton, 2000, p. 9.

20. D. Tutu, No hay futuro sin perdón, Nueva York, Doubleday, 1997, p. 54. 
La Comisión de la Verdad y la Reconciliación (TRC, por sus siglas en inglés) y la Recuperación de la Memoria Histórica (Remhi), así como la Comisión del Esclarecimiento Histórico de Naciones Unidas, eran muy distantes entre sí en el fin que perseguían y en los resultados (véase más adelante la tabla comparativa).

La amnistía ofrecida en el posapartheid en Sudáfrica contrasta fuertemente con la amnistía de Guatemala. En Guatemala, la amnistía fue parte del encubrimiento. En 1982, Ríos Montt proclamó una amnistía para todos los que, desde 1960, habían cometido crímenes por motivos políticos. Tal amnistía les dejaba la mano libre para cometer nuevos crímenes. Entre 1982 y 1988, fueron aprobadas una docena de leyes de amnistía. Y como parte de los Acuerdos de Paz, el Congreso aprobó en 1996 la Ley de Reconciliación Nacional, que, de nuevo, concedía amnistía. Las organizaciones de derechos humanos han desafiado la constitucionalidad de dicha ley, pues con ella muchos creen que será casi imposible enjuiciar a individuos por crímenes contra la humanidad ${ }^{21}$.

En Guatemala, la impunidad es un grave problema político y social. En 1996, el GAM (Grupo de Apoyo Mutuo), la Oficina de Derechos Humanos del Arzobispado de Guatemala (Odhag) y la Fundación Rigoberta Menchú Tum lanzaron una campaña en favor de una "Alianza Contra la Impunidad", en la que proponían la desmovilización y la reinserción de guerrillas, pero se oponían a una amnistía militar en general. En 2008, Naciones Unidas nombró la Comisión Internacional contra la Impunidad en Guatemala (Cicig), para que se ocupara de la impunidad en el país trabajando juntamente con el fiscal público, la Policía fiscal y otras oficinas gubernamentales, y también para que investigara los crímenes cometidos por miembros de grupos ilegales de seguridad y por estructuras de seguridad clandestina. La Comisión ha propuesto reformas legales para mejorar el sistema judicial. El español Carlos Castresana, quien ayudó a llevar a la justicia a Augusto Pinochet, encabezó la dirigencia de la Cicig, pero renunció en 2010, cuando fue nombrado Fiscal General de Guatemala una persona a quien se identificó como alguien cercano al crimen organizado (más tarde, grupos locales que trabajan por la justicia consiguieron que el Gobierno anulara este nombramiento).

21. Ver M. Popkin, "Ley Nacional de Reconciliación de Guatemala: ¿Combatiendo la impunidad o continuándola?", Centro para los Derechos Humanos Robert F. Kennedy, 1997. Disponible en www.juridicas.unam.mx/publica/librev/rev/iidh/ cont/24/dtr/dtr7.pdf. La Convención de los Derechos Humanos de la OEA, de la cual Guatemala es signataria, no permite amnistía o estatutos de límite para crímenes contra la humanidad, para ser promulgados por las naciones. Estoy muy agradecido con Dean Brackley por esta observación. 


\begin{tabular}{|c|c|}
\hline TRC & Remhi y CEH \\
\hline $\begin{array}{l}\text { La Comisión fue establecida por } \\
\text { la Constitución. Recibió 20,000 } \\
\text { declaraciones de las víctimas, } 2,000 \\
\text { de ellas en audiencias públicas, y } \\
8,000 \text { aplicaciones a la amnistía por } \\
\text { parte de los perpetradores, exigién- } \\
\text { doles hacer una confesión completa } \\
\text { de sus crímenes. }\end{array}$ & $\begin{array}{l}\text { La Comisión fue establecida por la } \\
\text { Iglesia católica y Naciones Unidas. } \\
\text { Remhi envió a } 700 \text { trabajadores de } \\
\text { la Iglesia a recoger testimonios. Se } \\
\text { presentaron muy pocos perpetradores. } \\
\text { Se consignaron los nombres de más de } \\
50 \text { mil víctimas. La CEH, con solo } 40 \\
\text { trabajadores, coincidió con las conclu- } \\
\text { siones de Remhi. }\end{array}$ \\
\hline $\begin{array}{l}\text { La Comisión tuvo autoridad casi } \\
\text { legal (por ejemplo, para poder citar } \\
\text { a los testigos). }\end{array}$ & $\begin{array}{l}\text { Las comisiones no tuvieron autoridad } \\
\text { legal. }\end{array}$ \\
\hline $\begin{array}{l}\text { Las audiencias de la Comisión } \\
\text { fueron transmitidas y comunicadas } \\
\text { en } 11 \text { idiomas. Los perpetradores } \\
\text { que se presentaron a la Comisión } \\
\text { fueron identificados, y se hicieron } \\
\text { públicas las decisiones sobre sus } \\
\text { solicitudes de amnistía. }\end{array}$ & $\begin{array}{l}\text { El trabajo de las comisiones fue privado. } \\
\text { En sus informes escritos, adjudicaron } \\
\text { culpas a los regímenes políticos, al } \\
\text { Ejército, a los insurgentes y a los patru- } \\
\text { lleros, pero sin identificar individual- } \\
\text { mente a los perpetradores. }\end{array}$ \\
\hline
\end{tabular}

Propongo tres distinciones por lo que toca al proceso penal en Guatemala. (1) Los soldados de infantería que cometieron crímenes capitales no deberían ser procesados. El proceso de los soldados de infantería rara vez trae sanación a las víctimas y puede polarizar aún más a la sociedad. Quedan demasiadas preguntas sobre lo que pasó y sobre el grado de su culpabilidad. (2) Varios políticos de alto nivel y oficiales militares que han sido acusados de crímenes en contra de la humanidad aún están en el poder, y ahora están ligados al tráfico de drogas. Las víctimas temen que el genocidio pueda comenzar otra vez, y que el pasado siga presente. Mientras no se procese a los autores de las masacres, las víctimas no sienten seguridad. Como alguien dijo, "nosotros queremos justicia, porque si no hay justicia, las masacres no terminarán”. Cuando los perpetradores continúan ejerciendo mucho poder y las víctimas casi ninguno, estas deben recuperar el poder político y social a través de la justicia y la reforma estructural ${ }^{22}$. Mi

22. Antjie Krog, periodista y poeta que cubrió los procedimientos CVR, lamenta con muchos otros el testimonio de F. W. de Klerk, el último presidente sudafricano bajo el apartheid, quien afirmó no saber de las atrocidades cometidas durante su presidencia. Ella escribió: "Seguramente, debe de haber alguien que puede dar la cara a las 'órdenes de arriba' para las operaciones". Ver El país de mi calavera, Londres, Jonathan Cape, 1998, p. 147. En tales culturas de negación, hay una gran dificultad en 
propuesta es que se adopten medidas especiales de castigo para quienes gobernaron el país y dirigieron al Ejército durante la perpetración de crímenes contra la humanidad. Se les debe prohibir ocupar un cargo político o tener un rango militar; y se les debe prohibir asociarse a partidos políticos. También se les debe prohibir reunirse con más de dos personas a la vez fuera de sus familias, publicar y hablar en público, salir del país o enviar dinero fuera del país. Si cometen nuevos crímenes o incitan a otros a cometerlos, están sujetos a un proceso penal. No hay aquí ninguna forma de amnistía.

(3) Los crímenes que se cometan en el presente, tráfico de drogas o actividades de las maras, como también los crímenes callejeros, deberían ser castigados. El juicio de traficantes de drogas, miembros de maras y criminales callejeros es necesario para sacarlos de las calles. Para ello, el sistema de justicia penal necesita ser reforzado. La anarquía ha socavado la confianza en la vigilancia que llevan a cabo los sistemas de justicia penal. Las autoridades municipales dan la espalda a los crímenes, y a menudo se sienten intimidadas para no investigarlos. La consecuencia de la impunidad es la actividad delictiva que ahora invade Guatemala: se estima que el $98 \%$ de todos los crímenes terminan sin ninguna acción judicial.

Al aplicar la justicia penal, los cristianos deberíamos tener en cuenta dos cosas. Tanto en la Escritura judía como en la cristiana la justicia de Dios es, con frecuencia, misericordiosa. El teólogo menonita John Yoder pone en contraste lo que ocurre en los reinos de este mundo, donde las ofensas son vengadas, con una "justicia de gracia" a la que nos llama el Espíritu de Dios. Los cristianos podemos apoyar la justicia que protege a la sociedad. Pero sin el elemento de misericordia, la justicia humana degenera en venganza. Permanece la tensión entre la justicia y la misericordia ${ }^{23}$.

La preocupación por la justicia penal debería extenderse a la reforma del sistema penitenciario en el que los convictos deben "pagar su deuda con la sociedad". En las cárceles de Guatemala, los que están en prisión y pertenecen a la élite social y política, y los que han cometido delitos que los demás reclusos juzgan como horrendos, es probable que sean asesinados por otros presos. Si sobreviven, pueden esperar acabar como víctimas de continuos asaltos. Esta es la cruda realidad en las prisiones guatemaltecas, verdaderas junglas que realmente

determinar la culpa. Como en Sudáfrica, los oficiales en Guatemala casi no dejaron huellas en el papel. Sin embargo, en 2005, diez millones de documentos fueron descubiertos en un depósito de municiones del Ejército y están ahora en manos del Procurador de los Derechos Humanos de Guatemala.

23. J. H. Yoder, Para las naciones: Ensayo evangélico y Público, Grand Rapids, William B. Eerdmans Publishing Company, 1987, pp. 228-229. 
impactan. Dejo a otros la reflexión sobre cómo las condiciones de la prisión son ya en sí mismas una forma de venganza.

\subsection{Justicia restaurativa}

Para que sean superadas las profundas divisiones en Guatemala, el Gobierno deberá enfrentar varias cuestiones en torno a cuál fue la responsabilidad de los Gobiernos anteriores en el genocidio ${ }^{24}$.

- La conmemoración pública de las víctimas ${ }^{25}$.

- Reparación a los sobrevivientes ${ }^{26}$. El asunto de las reparaciones causó un gran conflicto cuando Ríos Montt decidió indemnizar a las patrullas de autodefensa civil (patrulleros civiles), paramilitares creados por el Ejército, lo que obligó a 1.5 millones de hombres mayas y niños de más de catorce años a ingresar al servicio militar como si fueran a defender sus aldeas en contra de los insurgentes ${ }^{27}$.

- Reintegrar a la sociedad civil maya, a quienes fueron reclutados por la fuerza en el Ejército.

- Reforma del Ejército y de la Policía Nacional ${ }^{28}$.

- Tener en cuenta los problemas de justicia social. Una prioridad nacional deberían ser la salud, la educación y los proyectos económicos para mejorar la vida de los marginados ${ }^{29}$. Manuel dice que el único desarrollo económico en el que el Gobierno está realmente interesado es que crezca la prosperidad

24. En 2009, el presidente de El Salvador y el jefe de las fuerzas armadas reconocieron la responsabilidad del Gobierno durante la guerra civil (1980-1992).

25. He visto un monumento a las orillas de la plaza en Nebaj, que consiste en una pequeña placa y una pequeña paloma de concreto. Su cola cuelga con un pedazo de hierro y la pintura se está pelando.

26. El Programa Nacional de Resarcimiento, en un tiempo encabezado por Rosalina Tuyuc, fundadora de Conavigua, proporcionó pequeñas sumas a los familiares de las víctimas.

27. Efraín Ríos Montt causó indignación a las organizaciones de las víctimas y derechos humanos al solicitar apoyo de los patrulleros para su campaña electoral en 2003, prometiéndoles compensación por sus servicios durante 1980. Ríos Montt prometió 8,000 quetzales de compensación, pero únicamente fueron pagados Q200 (alrededor de \$25).

28. Jóvenes indígenas han formado una organización llamada Hijos e Hijas por la Identidad y la Justicia contra el Olvido y el Silencio (Hijos). Desde su fundación en 1995, el grupo ha trabajo para parar el desfile anual militar de Guatemala, que continúa a pesar de su prohibición por los Acuerdos de Paz. Ver la entrevista con Cecilia Gonzales en Presente: www.SOAW.org, invierno-primavera, 2009, p. 10.

29. Informe Remhi, op. cit., pp. 322-324. 
de los ricos y en marginar todavía más a los mayas. También hay problemas de bajo nivel de impuestos a los ricos y de evasión masiva de tributos.

Por lo que toca a la reincorporación de los soldados y de los patrulleros civiles a la comunidad, es muy pertinente la doctrina de los maya kekchí sobre la justicia restaurativa. En esa tradición, la justicia restaurativa eclipsa a la justicia penal y contiene elementos de misericordia. Así es como describe el "Código de conducta" (Pixab), publicado por guías espirituales mayas, la justicia restaurativa:

Es importante [tras haberse cometido un crimen grave] la restauración de la armonía. Si en lugar del perdón y la restitución de una persona culpable se decidió ponerla en prisión, esa persona ya no podrá transformarse como persona, ni será capaz de reparar el daño causado, ni mucho menos podrá cumplir con las responsabilidades con su propia familia. Todo ello aumentará el desequilibrio. Obviamente, en ese caso ser perdonado no consistirá puramente en quedar absuelto y renunciar a la justicia, sino que consistirá más bien en llegar a un acuerdo y un entendimiento la víctima y el victimario. Se hace así porque el primero en perdonar es el cosmos, la naturaleza y la divinidad, y por eso los seres humanos deben perdonar. Como el ser humano es perdonado por la divinidad, eso permite la restauración de la comunidad. Al principio y al final del proceso de solución de un problema, la parte culpable busca el perdón tanto de la parte ofendida como de las autoridades divinas de modo que no haya enfermedad en el futuro, pues aunque la justicia humana absuelve las faltas, no es suficiente para evitar futuros problemas. Lo más importante es la armonía iniciada por la divinidad. ${ }^{30}$

Lo que Tutu invoca como ubuntu en Sudáfrica, los mayas lo comprenden como la reincorporación de los individuos a la comunidad, sin la cual no tienen identidad.

Pasamos ahora a la función del perdón y de la reconciliación para el restablecimiento de la comunidad.

\section{El perdón}

Un punto de partida para considerar el perdón en Guatemala después de la guerra consistió en identificar quiénes fueron los responsables de asesinatos masivos y en qué grado. Se les puede catalogar en cinco grupos.

Primero, y con diferencia, los generales que ejercieron el poder político. Segundo, los oficiales del Ejército que dirigieron asaltos brutales. Tercero, los reclutados para el Ejército que cometieron los crímenes ${ }^{31}$. Cuarto, las fuerzas

30. Pixab', pp. 115-116. Traducción del autor.

31. Los reclutas fueron asignados a áreas alejadas de sus propias aldeas para que pudieran matar anónimamente. 
rebeldes que, según la $\mathrm{CEH}$, fueron responsables del $3 \%$ de las matanzas. Finalmente, los patrulleros civiles. La culpabilidad de los reclutados para el Ejército y de los patrulleros civiles son las más difíciles de establecer. Los mayas que se resistían eran amenazados con la muerte. Su instrucción consistía en métodos de brutal entrenamiento y en un adoctrinamiento que los condicionaba a matar. Escribe Michelle Tooley que "los miembros de la familia a menudo cuentan historias de hijos y hermanos que, después de su servicio en el Ejército, regresaron a sus aldeas como personas cambiadas. Miembros de la familia describen los cambios como si 'hubiesen convertido a mi hijo en un animal' con el lavado de cerebro a los que les sometían" ${ }^{32}$. Los patrulleros civiles, 1.5 millones de hombres mayas y niños de catorce años en adelante fueron obligados bajo pena de muerte a patrullar sus aldeas, y algunas veces eran los perpetradores conocidos por los sobrevivientes. Una mujer dijo que "los que nos han hecho daño todavía están vivos. Están viviendo en la aldea Salinas Magdalena" ${ }^{33}$. Sin embargo, si la posibilidad del perdón requiere el conocimiento de quién fue el responsable del daño causado, entonces el perdón se hace problemático. Pues como dijo una viuda, "yo ni siquiera sé a quién perdonar".

A la pregunta de si el perdón es posible, he escuchado cuatro respuestas. La primera es la negativa rotunda a perdonar y, en su lugar, el deseo de venganza. Una mujer dijo: “Todavía hoy siento (el crimen) más aquí, pensando en todas esas cosas (...) Y a veces el resentimiento brota en mí, y a veces pienso contra quién tomar represalias" ${ }^{34}$. Otro sobreviviente acusó con amargura a los perpetradores de "no tener vergüenza por las matanzas que cometieron", pero se sentía impotente para tomar represalias por miedo a las consecuencias. Otros sobrevivientes dijeron que ellos acudían a adivinos para ocasionar daño a los malhechores. Algunas mujeres dijeron que en privado habían hecho bromas degradantes contra el jefe local, responsable de crímenes horrendos y que aún retenía el control de las aldeas. Aunque ha habido llamadas para poder enjuiciar a los culpables, ha habido muy pocos actos de represalia ${ }^{35}$. Un trabajador de la pastoral contó el testimonio de "Mario", quien venció su deseo de venganza.

Crecí sin mi padre. Él fue asesinado durante la violencia. El hombre que vi como el responsable de su muerte vive en nuestra aldea. Yo crecí odiándolo. Fue aún peor cuando pasó a ser ministro de la comunión en nuestra aldea. Cuando yo era un adolescente, le dije a un hombre cerca del pueblo quién asesinó a mi padre y el odio que le tenía. Él dijo que era muy fácil matarlo, solo que le diera dinero y él vería que este hombre fuera asesinado. Yo estuve en agonía durante dos semanas. Tenía que decidir vengar o no la muerte de

32. M. Tooley, Voces de los sin voz, Scottdale, Herald Press, 1997, p. 108.

33. Informe Remhi, op. cit., p. 50.

34. Remhilbid., p. 3.

35. J. N. Zur, Memorias violentas, op. cit., p. 122. 
mi padre. Luego me hice de la idea. No soy un asesino. No puedo tomar la vida de otro. Yo perdono la vida del asesino de mi padre y él ni siquiera lo sabe. Hoy en día tengo mi negocio y le he prestado dinero al hijo de este hombre cuando ellos tenían necesidades económicas. Lo que yo quiero decir aquí es que si yo perdoné al asesino de mi padre, a quien conozco, ¿por qué debería de participar en la muerte de un hombre acusado y linchado, a quien ni siquiera conozco? Yo no participo en linchamientos. ${ }^{36}$

Un segundo grupo expresó la disposición de ser "tolerantes" con los culpables. Un maya achí insistía en que "el perdón no está en nuestra lengua. Esta idea de perdón viene de las organizaciones no gubernamentales (ONG). Los culpables dicen: 'Nosotros hicimos estas cosas malas bajo órdenes de otros, perdónenme'. Pero ese perdón no tiene significado para mí porque no existe perdón en achí" ${ }^{37}$. Sí habló de un agresor que solo pedía: "Tolérenme un poquito". Es lo más que se podía esperar.

Un tercer grupo estaba dispuesto a otorgar perdón condicional a los ofensores si reconocían su culpa y reparaban su crimen. Los guías espirituales de los mayas quiché describieron así la restauración de la armonía después de una ofensa contra la comunidad:

En la vida, y especialmente en la resolución de conflictos, entre los ancianos se observa un principio de perdón. Consiste en conceder el perdón a alguien que ha cometido algún crimen, pero únicamente cuando muestra un cambio de actitud y de conducta y está de acuerdo con hacer restitución por el daño causado por la violación de una norma. ${ }^{38}$

Un cuarto grupo expresó el punto de vista cristiano de perdón. Manuel le pidió a Dios que le diera la capacidad de perdonar a quienes asesinaron a su familia $^{39}$. Dijo que dejaba el juicio a Dios. Para Manuel, el perdón no depende de llevar ante la justicia a quien hubiese asesinado a su familia. El perdón no tiene por qué ser más fácil si se ha hecho justicia. Manuel también expresa compasión de quienes ve como cómplices involuntarios de la brutalidad del Ejército. Nos contó el ejemplo de un conocido suyo que tuvo que enfrentarse con la siguiente

36. El trabajador de pastoral guatemalteco envió al autor esta historia y las que siguen en un correo electrónico. Ha pedido que su identidad y lugar de residencia no sea revelado.

37. V. Sanford, Secretos enterrados, op. cit., p. 271.

38. Conferencia Nacional de Ministros de la Espiritualidad Maya, Uxe'al Pixab' Re Amaq' (Fuentes y fundamentos del derecho de la nación maya), Ciudad de Guatemala, 2001, pp. 115-116. Traducción del autor.

39. Las siguientes observaciones e historias de Manuel fueron relatadas al autor en una entrevista en julio de 2009. 
opción: matar a su propio tío o ser asesinado. Manuel no lo considera culpable, mientras que el predicador pentecostal del lugar juzgó que no podría salvarse.

El perdón del otro ocurre cuando aceptamos que Dios perdona nuestras ofensas. En El perdón encarnado: Un análisis teológico, L. Gregory Jones recuerda que para los cristianos, el ofrecimiento de perdón debe ser otorgado a los ofensores, tengan o no tengan la disponibilidad de expresar remordimiento y arrepentirse, o de pedir perdón por sus crímenes. Jones hace notar que esta comprensión del perdón que tienen los cristianos queda distorsionada "si se hace del arrepentimiento un requisito para el perdón" ${ }^{\text {. }}$. Pero sí puede jugar un papel esencial: "Insistir en la importancia del arrepentimiento es una forma de garantizar que se toma en serio la culpa y la responsabilidad, y de no ignorar los pecados concretos que han cometido no solo contra Dios, sino el uno contra el otro" ${ }^{41}$.

Manuel cuenta esta historia:

Conozco a un hombre que estaba en una posición de dar órdenes para eliminar a la gente en esta aldea. Se fijaba en los que habían ido al Ejército a dar nombres de gente que, supuestamente, se había involucrado en la guerrilla. Esta era su manera de evitar que ocurrieran más muertes. Él mismo había perdido dos hijos en un ataque del Ejército a su comunidad. Ahora vive con un dolor constante por lo que él hizo a otros. Ha ido a confesarse con un sacerdote y después decidió contarlo todo a su esposa, a sus hijos e hijas. Para él fue terrible admitirlo a su familia. Todos ellos rezaron juntos una novena por cada una de las almas de los que él había matado. Ahora está muy activo en proyectos de la comunidad, en un esfuerzo por trabajar ahora por la vida y no por la muerte. Ha trabajado para que haya agua en las casas de la gente. Una de sus actividades principales es trabajar en la reforestación. Pero a pesar de todo esto, no siente que ha hecho suficiente. Ahora está pensando en ir a ver a los familiares de sus víctimas y pedirles perdón, [aunque] algunas personas le han advertido que él podría ser linchado y que es mejor no hacerlo, pues ocurre mucho en el quiché, y ha ido aumentando con el tiempo.

En un testimonio de Remhi, ha quedado grabada así la necesidad de arrepentimiento de un agresor: "Tal vez Dios me perdonará (...) Es por eso que he venido a decirlo (...) Se siente bien al decirlo, es como una confesión"².

Un trabajador pastoral relata otra historia de perdón y arrepentimiento:

"Isabel", la viuda de un hombre asesinado por la violencia, se enojaba mucho siempre que veía a "Felipe", el hombre que era para ella el responsable de la

40. L. G. Jones, El perdón plasmado: Un análisis teológico, Grand Rapids, William B. Erdmann's Publishing Company, 1995.

41. Ibid., p. 150.

42. Informe Remhi, op. cit., p. 23. 
muerte de su esposo, y estaba en el mismo programa de liderazgo en el que ella participaba. Un día se enojó tanto que le decía a gritos lo que tenía contra él, y quería pegarle públicamente. El equipo de la parroquia sugirió que comenzasen un proceso de reconciliación. Había que nombrar un equipo de reconciliación que trabajase con ambas partes por separado, y después tener una reunión todos juntos. En la primera reunión, Isabel le dijo a Felipe todo lo que la familia tuvo que pasar después de la muerte de su esposo: todos los años de hambre, el sufrimiento con sus niños. Ella tuvo que construir su casa de adobe con sus propias manos y sus niños no fueron a la escuela a causa de su pobreza. Por eso, ahora que son adultos no tienen trabajos decentes. Le recordó a Felipe que él fue quien dio al Ejército el nombre de su esposo, y si él no hubiera dado nombres, hoy estaría vivo su esposo, no Felipe. Entre otras cosas, lo llamó Judas. Felipe se arrodilló y respondió que él había dado los nombres bajo torturas del Ejército, que él había perdido un ojo y que había perdido su aldea porque tuvo que marcharse a otra aldea. Cuando contaba esto, los hombres lloraron con Felipe. Las mujeres fueron al lado de Isabel. El sacerdote estaba llorando porque él mismo había perdido a dos de sus hermanos por la confesión de Felipe al Ejército. Se tuvieron más reuniones, pero al final se puso la culpa donde estaba. La verdadera culpa era del Ejército porque ellos habían presionado tanto a Felipe y a la aldea, ellos habían torturado y asesinado. Sin embargo, Felipe quería hacer una reparación material a Isabel. Le dio una máquina de coser que él tenía para que su hijo pudiera vivir vendiendo a los turistas chaquetas típicas. También le dio un árbol de eucalipto para que lo plantara en su tierra. De repente, ambos se sintieron libres, y ocurrió algo maravilloso: conseguir que se hiciera realidad el liderazgo que ambos enseñaban. Ambos comenzaron en sus aldeas proyectos de Letrina Abonera Seca Familiar. Después, ambos empezaron programas de forestación. Y más tarde, comenzaron la agricultura orgánica con los grupos de sus aldeas. Sus grupos se reunían ocasionalmente para compartir sus experiencias en los proyectos. Y cuando esto ocurría era una ocasión alegre.

A mi modo de ver, el perdón es algo personal e íntimo. Es algo que únicamente pueden dar quienes han sido agredidos. Y es un proceso agonizante. Dos condiciones son necesarias para que las víctimas puedan perdonar. La primera es que recobren su sentido de actuar y su capacidad personal. Mientras vivan en un estado de insensibilidad, de limitación personal y de susto ("pérdida del alma"), permanecen estancadas. La segunda es que las víctimas tengan un sentido de seguridad que proviene de la confianza en que la violencia no volverá a repetirse. Algunos programas de salud mental ya han empezado a tratar estos problemas.

Manuel ve una diferencia entre los que pueden perdonar y los que no pueden. Quienes han recibido alguna ayuda psicológica - Manuel fue uno de ellos - han 
tenido más capacidad de perdonar ${ }^{43}$. Sin ayuda psicológica, "nosotros llevamos las heridas abiertas que hacen que el verdadero perdón sea muy difícil". Sin ayuda, esas personas "únicamente tratan de olvidar", pero el resentimiento está siempre presente. El resentimiento es "el odio e impotencia en el rostro del agresor". Cuando hay algo de sanación, "es posible verdaderamente perdonar, aun cuando el agresor no se arrepienta". El perdón, anota un trabajador pastoral, puede tener un profundo efecto:

El perdón es tan importante para la libertad emocional de los culpables como para la de las víctimas, y es increíble el poder que tiene de dar vida. Las víctimas, como las viudas que eran impotentes cuando fueron victimizadas, ahora tienen el poder en sus manos. Tienen el poder para liberarse de sí mismas y de los culpables. Dan a todos la oportunidad de vivir una nueva vida.

Lo que quisiera llamar un "perdón profundo" ocurre cuando la víctima (como en el caso de Miguel) ha llegado a tener compasión del agresor y desea su bien$\operatorname{estar}^{44}$. ¿Cuál es el rol de la Iglesia? Los sacerdotes y pastores ¿deben simplemente llamar al perdón? Hablar del perdón como de una obligación solo sirve para hacer más profunda la depresión de quienes no son capaces, psíquicamente, de perdonar. Incluso para decir que todos tenemos necesidad del perdón de Dios, se necesita una gran sensibilidad pastoral. Las víctimas conocen demasiado bien la tenebrosidad de los seres humanos, y han tenido que lidiar con la pregunta de dónde estaba Dios en todo este sufrimiento. Lo que la Iglesia debería hacer es anunciar que, a través de Cristo, hay promesa de una vida nueva - la resurrección - ya ahora. Esta es la buena noticia tanto para las víctimas como para los victimarios.

\section{Reconciliación}

Miroslav Volf es un croata que fue testigo de la desintegración de Yugoslavia (1992), de la horrorosa "limpieza étnica" que llevaron a cabo los serbios y de las represalias que siguieron por parte de los croatas y los musulmanes. En Exclusión y abrazo, Volf se adentra en el proceso de reconciliación ${ }^{45}$. La describe como un proceso de transformación, a la vez, de las identidades de los individuos y de los acuerdos sociales. La posibilidad de reconciliación exige, en definitiva, abrazar al "otro" respetando la diferencia de él o de ella.

43. El programa, auspiciado por la Universidad Rafael Landívar, ha trabajado en su comunidad.

44. Para una explicación particularmente detallada sobre el perdón, recomiendo altamente a P. Gobodo-Madikizela, A Human Being Died That Night: A South African Story of Forgiveness, Boston, Houghton Mifflin Company, 2003. Ella estudió el caso de un operativo de seguridad que fue responsable de la muerte de muchos negros sudafricanos.

45. M. Volf, Exclusion and Embrace: A Theological Exploration of Identity, Otherness, and Reconciliatio, Nashville, Abington Press, 1996. 
En Guatemala, la intención del Acuerdo de Paz de 1996 era transformar el ordenamiento social. Entre otras cosas, llamó a reconocer los derechos de los pueblos indígenas, los de las mujeres, la concesión de tierra a los pobres y la reforma de la Policía militar y nacional. Esta lucha por crear más ordenamientos sociales justos continúa en la medida en que los activistas trabajan en favor de la justicia penal y restaurativa, la protección de los derechos humanos y la justicia social.

Para que pueda haber transformación del ordenamiento social, Volf se fija especialmente en la necesidad de transformar la propia identidad de los individuos que viene de la fe cristiana. Monseñor Julio Cabrera Ovalle, obispo de Quiché, en honor del asesinado monseñor Gerardi publicó una serie de ensayos de teólogos de pastoral, que han trabajado en Quiché desde el comienzo de la violencia ${ }^{46}$. Tema común en todos ellos es que la reconciliación es un proceso de tejer vínculos entre personas que están profundamente alienadas. Como escribió monseñor Gerardi en el reporte Remhi, la reconciliación requiere una profunda conversión. En casi todos los ensayos se hace referencia a la parábola del hijo pródigo.

Volf describe en cuatro pasos lo que significa que quienes están alienados unos de otros pueden abrazarse los unos a los otros. En primer lugar, deben abrir sus brazos para alcanzar al otro, reconociendo que algo falta en su propia identidad y que no son autosuficientes, sino que viven "en el dolor de [la] ausencia del otro" ${ }^{47}$. Abrir los brazos, prosigue Volf, "es un símbolo de que yo he creado un espacio en mí mismo para que el otro pueda entrar". En segundo lugar, el deseo de abrazar conlleva incertidumbre. En lugar de forzar o manipular un abrazo, hay que esperar con esperanza la reciprocidad del otro. En tercer lugar, cuando hay reciprocidad, podemos cerrar nuestros brazos, no sometiéndonos a los otros o exigiéndoles que dejen de ser lo que son, sino aceptándolos. En cuarto lugar, volver a abrir los brazos es una señal de que el otro queda libre para ser quien es.

Abrazar al otro comienza por reconocer la propia culpa. Es comprensible centrarse en la propia inocencia. En la mayoría de las comisiones de la verdad, el énfasis se pone a menudo en las víctimas. Ellas son las que hablan. Los victimarios - con raras excepciones - quedan en la sombra y en silencio. Al presenciar las atrocidades en los Balcanes, Volf puede decir que no hay "inocencia absoluta" ni "culpa absoluta". El pecado está presente en todas partes, el mal infligido a las víctimas a menudo resulta en victimización reactiva, si no contra los agresores, sí contra otros. La consecuencia del mal es una pérdida de inocencia en muchas de las víctimas. Volf no dice que la presencia universal del pecado disminuye la culpa de profundas injusticias. Lo que afirma es que la cruz de Cristo es la reve-

46. J. Cabrera Ovalle (ed.), Memoria y testigos de Guatemala, Ciudad de Guatemala, Ediciones San Pablo, 2001. El volumen está dedicado al obispo Gerardi, su predecesor en el K'iche'.

47. M. Volf, Exclusion and Embrace, op. cit., p. 141. 
lación de la solidaridad divina con las víctimas y la expiación por lo que hacen los agresores. El mal que describe Volf queda reflejado en las múltiples fallas en la actual Guatemala. Fernando Suazo, psicólogo y teólogo pastoral, describe así la violencia que permea Guatemala: hombres violando a mujeres, adultos violando a niños, grupos religiosos profundamente hostiles los unos contra los otros, pobres luchando unos contra otros ${ }^{48}$. Suazo reconoce la ausencia de acogida en la posguerra de Guatemala. Recuerda lo que dijo una persona maya: "Hemos perdonado a quienes mataron a nuestros niños, pero no hablaremos con ellos. Cruzaremos al otro lado de la calle para evitarlos" ${ }^{\prime 9}$. De igual modo, la posibilidad de acogida queda bloqueada porque los victimarios rara vez se acercan a sus víctimas. Es la distancia personal. Impide el encuentro personal y la reconciliación y restauración de la comunidad. Todavía no hay abrazo.

J. P. Lederach, un menonita comprometido en la construcción de la paz y la reconciliación desde Nicaragua hasta Irlanda del Norte, dice que la reconciliación es un lugar y un foco iluminador, una intersección donde las verdades de las injusticias pasadas se encuentran con futuros de misericordia y compasión. Lederach la describe como "un encuentro entre la expresión abierta de un pasado doloroso, por un lado, y la búsqueda de articulación de un futuro interdependiente a largo plazo" ${ }^{50}$. Esta intersección de "tiempo y espacio" da a las personas alienadas la oportunidad de compartir el dolor mutuo que han sufrido, y empiezan a imaginarse un futuro basado en la compasión mutua. Lederach ha trabajado con comunidades que se dividieron por el conflicto para poder encontrar ese espacio. Describe la experiencia de un equipo religioso de conciliación en Nicaragua para mediar en un conflicto entre el Gobierno sandinista y el movimiento de resistencia indígena. Las sesiones de negociación en varios lugares comenzaban con la lectura del Salmo 85: "El amor y la verdad se dan cita, la justicia y la paz se besan" $(85,11)$. Los participantes fueron invitados a discutir cada uno de estos conceptos "como si se tratara de una persona, describiendo las imágenes que traían a la mente, y qué es lo que cada uno tenía que decir sobre el conflicto". Las discusiones fueron muy valiosas y los grupos concluyeron que el lugar donde esto podría ocurrir es en la reconciliación.

Las Iglesias son lugares donde puede ocurrir la acogida de la que habla Volf y el espacio donde pueden encontrarse la justicia y la misericordia de que habla Lederach. Monseñor Gerardi, durante la presentación del informe Remhi, dijo: "Estamos llamados a la reconciliación. (...) La presencia de Cristo nos llama a la reconciliación. (...) La conversión es necesaria, y depende de nosotros abrir

48. F. Suazo, "La reconciliación compromete los corazones", en Memoria y testigos, p. 249. Las traducciones de todos estos ensayos son del autor.

49. Ibid., p. 250.

50. J. P. Lederach, Construyendo la paz. Reconciliación sostenible en sociedades divididas, Washington D. C., United States Institute of Peace Press, 1997, p. 31. 
espacios para lograr la conversión" 51 . Mario Molina, actual obispo de Quiché, escribe: "Somos portadores (...) de dirección y esperanza, de perdón y gracia, de verdad y de libertad. Como testigos de Cristo, somos sembradores de semillas de fraternidad sin exclusión, de dignidad sin prejuicio" 52 .

Y reta a la Iglesia: "En qué medida hemos contribuido como Iglesia a detener la violencia?” ${ }^{3}$. "Estamos contribuyendo a la reconstrucción de una nueva nación o nos quedamos al margen de estos esfuerzos?" 54 .

Cáritas es el organismo de pastoral social de la Iglesia católica en Quiché. A través de sus programas, trabaja por la reconciliación y la transformación tanto de los acuerdos sociales como de la autoidentidad individual. En su esfuerzo por equilibrar la estructura de poder, Cáritas imparte conocimientos sobre negociación y mediación para empoderar a quienes han sido excluidos del proceso político. Recientemente ayudó a personas mayas a resistir pacíficamente la impunidad. Un policía local había secuestrado a dos mujeres, y violó y mató a una de ellas. Los miembros de la comunidad protestaron masivamente, se enfrentaron con la Policía y hablaron con las autoridades locales para que se procesase y castigase al autor. El enfoque de la comunidad consistió en identificar al responsable, mientras aseguraban a la Policía que consideraban que ese crimen era una excepción en la conducta de la institución local. Acusar a un agente era algo casi inaudito. El policía fue declarado culpable y sentenciado a 50 años de prisión. El año pasado, se escapó de la cárcel, pero unos meses después, volvió a ser capturado. Ahora continúa su vida en la prisión.

Cáritas prepara a los líderes de la comunidad para solucionar conflictos. Y a su vez, estos líderes enseñan a los demás en sus comunidades. También enseñan métodos de cooperación para tratar más efectivamente las necesidades económicas, sociales, educacionales y de salud de la comunidad. Este es el camino para superar el aislamiento, la anomia, la falta de capacidad social, la desintegración de las comunidades y el sentido de impotencia. Los ejercicios prácticos de Cáritas están destinados a la población analfabeta. Y pueden ser reproducidos fácilmente por quienes han sido entrenados por la organización en las comunidades.

Martin Luther King hijo hizo notar que el racismo es doblemente corrupto: roba a las víctimas su propia estima, ya que interiorizan un sentido de inferioridad, y al racista le da un falso sentido de superioridad. Ambos sentidos, de inferioridad y de superioridad, deben ser superados. Para poder abrir los propios

51. Informe Remhi, op. cit., p. xxiii.

52. Mario Molina, "Lectura Ornate del Informe Guatemala: Nunca más", en Memoria y testigos, op. cit.

53. Ibid., p. 171.

54. Ibid., p. 176. Traducción del autor. 
brazos y dar inicio a la acogida al otro, es necesario que los individuos recobren el sentido de autogestión. El trabajador pastoral que he citado antes describe así cómo se inicia el proceso:

Algunos que trabajan en reconciliación afirman que es necesario seguir los siguientes pasos. Reconocerme a mí mismo como una víctima de la injusticia, verbalizar mi verdad y mi sufrimiento, y pasar un período de señalar a los responsables. Después, debo seguir y caer en la cuenta de que soy realmente un sobreviviente. Captar las fuerzas que me han permitido sobrevivir, sacar fuerza de ellas y empezar a hacer cosas que son para mí pruebas de que estoy vivo, y de que hoy puedo proponerme hacer cambios en la vida de mi familia y de la sociedad para que la historia no se repita. Finalmente, podré considerarme como una persona sanada cuando reconozca que mis acciones políticas y personales ya no provienen de mis heridas, sino de mi fuente de vida o de mi espíritu. ${ }^{55}$

Hay dos imágenes del Evangelio que ofrecen una visión de reconciliación en Guatemala. La primera es la imagen del Reino de Dios proclamado por Jesús. Para los cristianos, el Reino de Dios, de amor y de justicia, es el modelo al que aspiran los acuerdos sociales. La proclamación de Jesús de la buena noticia a los pobres, la libertad de los cautivos y la creación de relaciones sociales justas significan que "el Reino ha llegado". Una segunda imagen es la parábola del hijo pródigo como la cuenta Jesús. Solitario y compungido por la culpa, el hijo pródigo es ahora acogido por su padre. La alienación ha sido superada.

A las comunidades cristianas de Guatemala se les ha confiado el gran desafío de superar la alienación entre las víctimas y los victimarios. Como señala Volf, así como en la cruz de Cristo la solidaridad de Dios "sufre con las víctimas, las protege y les da los derechos de los que han sido destituidas... así debemos hacerlo nosotros". La gran tarea que nos queda es dar la bienvenida a la comunidad a los que han sido excluidos por sus crímenes y su culpabilidad. Por el don de Dios, "los impíos no son abandonados a su maldad", sino que son recibidos "dentro de la comunión divina a través de la expiación". Nosotros debemos hacer lo mismo, "quien quiera que sean nuestros enemigos y quien quiera que seamos nosotros" $"$. Estas son las tareas de inclusión, acogimiento y reconciliación.

\section{Conclusión}

En su obra Purgatorio, Ariel Dorfman se pregunta: “iPuede haber perdón y reconciliación si hemos cometido hechos monstruosos?" 57 . En la obra, una

55. Este comentario fue hecho al autor en una carta de agosto de 2010.

56. M. Volf, Exclusion and Embrace, op. cit., p. 23.

57. A. Dorfman, Purgatorio, Londres, Nick Hern Books Limited, 2006. "Epílogo", pp. 44,45 . 
mujer y un hombre, que son esposa y esposo, se han causado heridas terribles y no parecen sentir ningún remordimiento. Dorfman analiza cómo y cuándo se puede romper el ciclo de la venganza, y si "puede haber algún tipo de reparación y algún rastro de redención". ¿Es posible el arrepentimiento y la reconciliación? En el desarrollo de la obra, las víctimas y los victimarios se confrontan consigo mismos. Finalmente, en forma agónica confiesan las dolorosas verdades de asesinato y traición. Al final, aparece la identidad de ambos. Él es Cortés, el conquistador que despojó y abandonó a la Malinche, su amante y traductora indígena, junto con sus hijos por una mujer de piel clara. Ella mató a los hijos de ambos. La pregunta final de Dorfman es si el mal puede ser superado por el amor, lo que es "urgente en este mundo nuestro contaminado por la violencia, el miedo y la traición"58. Al final de la obra, el hombre reconoce que si ellos han de liberarse a sí mismos de su dolor, de alguna manera tienen que perdonarse el uno al otro. "Puede llevar un largo tiempo", dice él, pero "no tengo ningún otro lugar a donde ir".

En este artículo hemos explorado la posibilidad de sanación social en Guatemala a través de la justicia, el perdón y la reconciliación. Hablamos de todas estas cosas, aunque quizás no coincidimos en lo que son y en cómo se relacionan entre sí. En Guatemala, la justicia penal sigue siendo una meta lejana, y he sugerido tres tipos de justicia penal. A la larga, la justicia reforma los sistemas que han causado destrucción en la vida de muchos. Para el obispo Tutu, hay que alcanzar "gran justicia moral" con la ayuda de la Comisión de la Verdad y Reconciliación, lo que ofrece una intuición muy importante en la búsqueda de la justicia penal. La justicia restaurativa, en alguna de sus formas, es posible en Guatemala y es un componente importante de sanación.

El perdón toma diferentes formas y solo se puede alimentar con exquisita sensibilidad. Requiere de volver a sentir la vida de personas que han sido severamente oprimidas. Las personas no perdonan a los sistemas; a los sistemas se les reforma. Pero sí se puede perdonar a personas que fueron agentes de esos sistemas. ¿Quién va a decir que en definitiva no puede haber perdón, que el deseo de venganza o de "tolerar un poco" no puede acabar "cruzando la calle" para ir hacia el otro e incluso compartiendo un banquete? Habrá que decir la verdad para que las víctimas puedan sanar y para que sus sufrimientos no caigan en el olvido. Pero misteriosamente, la compasión puede moverse en ambas direcciones. Los victimarios pueden mirar a los ojos de las víctimas y a través de ellos ver corazones destrozados. Las víctimas pueden mirar a los ojos de los victimarios y ver, a través de ellos, que han quedado sin humanidad.

La reconciliación es una meta a largo plazo que empieza a alcanzarse cuando los beneficiarios del sistema reconocen su complicidad y reconocen la dignidad humana de las víctimas. La reconciliación es el trabajo de muchas personas

58. Ibid., p. 46. 
que se han comprometido a sí mismas con cambiar sistemas del mal. Es una responsabilidad social. Empieza cuando la luz ha iluminado la verdad, y ese es el trabajo de las comisiones de la verdad. Se necesita que la verdad se diga para que todos la oigan. La Comisión de la Verdad y Reconciliación permitió que la verdad fuese dicha para que no pudiesen prosperar las distorsiones que hacían los autores y los agentes del apartheid. Pero, a diferencia de lo ocurrido en Sudáfrica, en Guatemala las verdades del informe Remhi y de la Comisión para la Clarificación Histórica, las verdades de miles de individuos, todavía siguen sepultadas en gran parte en voluminosos informes, y no han sido ni vistos ni escuchados en los medios de comunicación masiva.

Manuel nos ofrece una interesante observación sobre otra forma más amplia de reconciliación. Describe los años de guerra y destrucción como un atropello del orden cósmico porque los políticos y los ejércitos trataron de usurpar el poder de Dios. Manuel cree que el orden cósmico está siendo restaurado porque quienes lo han trastornado están perdiendo poder. "La guerra fue un tiempo en el que los seres humanos pensaron que eran tan grandes como Dios. Esto es lo que fue el Ejército y los autores intelectuales de las matanzas masivas. Pero ahora se ha restaurado el orden propio de los humanos. En aquella época no podíamos ver a Dios, pero ahora volvemos a sentir su presencia. La soberanía de Dios vuelve a estar de manifiesto".

Manuel es miembro del equipo pastoral de la parroquia. Está a cargo de la emisora de radio de la parroquia que transmite lecturas de la Biblia, reflexiones espirituales y música a unas noventa aldeas alrededor de las montañas de los Cuchumatanes. Tiene la esperanza de que sigan siendo importantes las comisiones de la verdad de la Iglesia, los entierros con dignidad de las víctimas, el cuidado de la salud mental y el trabajo de Cáritas. Ciertamente, todavía queda mucho por hacer en la sanación.

Cuando escribíamos este ensayo, Jesús Tecú Osorio, un guatemalteco activista de los derechos humanos, recibió el Primer Premio de Derechos Humanos. Lo saludo a él y a otros muchos miles que, como él, valientemente, buscan justicia y paz.

\section{Epílogo}

En octubre de 2011, Álvaro Colom, presidente de Guatemala, pidió perdón a la familia de Jacobo Arbenz, quien había sido elegido democráticamente y cuyo Gobierno fue derrocado por un golpe de Estado en 1954. El presidente Colom se refirió al golpe como un "crimen cometido [contra] la sociedad de Guatemala por la CIA y por guatemaltecos con malas intenciones". Colom dijo: "Quiero pedir perdón a la familia de Arbenz Vilanova por este horrendo crimen" del cual 
"aún no nos hemos recuperado" 59 . Como un paso más en la recuperación de la memoria histórica, Colom anunció que los libros de texto escolares volverían a ser escritos para añadir el legado de Arbenz al país, y que se volvería a nombrar en su memoria la carretera al Atlántico. Colom subrayó el papel importante de la CIA, de Estados Unidos, en el golpe de Estado, que fue una respuesta al temor de la United Fruit Company de que Arbenz iba a expropiar las tierras no cultivadas de los indígenas pobres de Guatemala. "Aquí empezó la injusticia, y hago un llamado a los Estados Unidos para que reconozcan (sic) sus errores". El Gobierno de Colom, sin embargo, no pidió perdón por las casi cuatro décadas de las juntas militares responsables de enormes sufrimientos para el pueblo de Guatemala. Tampoco ha pedido perdón Estados Unidos, como arquitecto del golpe de Estado que llevó a treinta y seis años de guerra civil. Lo menos que se puede decir es que las disculpas son muy pequeñas y han llegado demasiado tarde.

59. Según Reuters, 21 de octubre de 2011. 